\title{
Impulse Oscillometry as a Predictor of Asthma Exacerbations in Young Children
}

\author{
Johannes Schulze ${ }^{\mathrm{a}}$ Silke Biedebach $^{\mathrm{a}}$ Martin Christmann ${ }^{c}$ Eva Herrmann ${ }^{\mathrm{b}}$ \\ Sandra Voss ${ }^{\text {a }}$ Stefan Zielen ${ }^{\text {a }}$

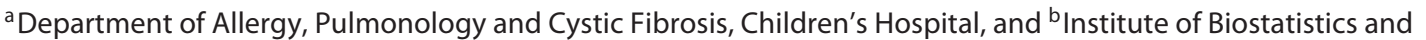 \\ Mathematical Modeling, Goethe University, Frankfurt am Main, Germany; ${ }^{\complement}{ }^{C}$ Children's Hospital, Zurich, Switzerland
}

\section{Key Words}

Pediatric asthma · Exacerbation · Predictors · Impulse oscillometry · Pediatric lung function testing $\cdot$ Methacholine inhalation challenge

\begin{abstract}
Background: In a post-hoc analysis of a pediatric asthma study, we identified the predictors of asthma exacerbations $(\mathrm{AEs})$ and related them to forced expiratory volume $\left(\mathrm{FEV}_{1}\right)$, the $\mathrm{FEV}_{1} / \mathrm{FVC}$ ratio, and bronchial hyperresponsiveness (BHR). Objectives: We sought to detect predictors of AEs in a prospective study that utilizes impulse oscillometry (IOS) and to compare the results to previously determined predictors. Methods: A moderate AE was defined as an increased use of salbutamol during coughing episodes. Pulmonary function and BHR were measured during symptom- and medication-free periods. Additionally, allergen testing and IOS were included. To calculate the sensitivity and specificity of $\mathrm{AE}$ detection, a receiver-operating characteristic (ROC) curve was plotted, and accuracy was measured with the area under the ROC curve (AUC). A logistic regression analysis was used to predict the probability of an exacerbation. Results: Seventy-five pediatric patients (4-7 years of age) with intermittent asthma were included. In 69 patients, the following cut-off values demonstrated the best sensitivity and speci-
\end{abstract}

ficity combination for predicting an AE: FEV 1 103.2\% (AUC 0.62), BHR ( $P D_{20}$ methacholine) $0.13 \mathrm{mg}$ (AUC 0.61), and, in 54 children, Rrs5 $0.78 \mathrm{kPa} \times \mathrm{I}^{-1} \times \mathrm{s}$ (AUC 0.80). Logistic regression analysis demonstrated that the combination of all parameters predicted the individual risk of AEs with an accuracy of $86 \%$. Conclusions: IOS, a simple method, predicted the probability of AEs in young children. Airway resistance, measured by IOS, was superior to $\mathrm{FEV}_{1}$ and methacholine testing. The current data suggest that peripheral airway obstruction is present during symptom-free periods and that these children more likely experience AEs.

(C) 2016 S. Karger AG, Basel

\section{Introduction}

In childhood asthma, acute exacerbations are one of the main causes for emergency department visits [1-5]. Whereas the use of anti-inflammatory therapy in moderate to severe asthmatics is well established, strategies to prevent asthma exacerbations (AEs) in young children with intermittent asthma are unclear. To avoid overtreatment with anti-inflammatory medication, it is very import to define risk factors that can predict further AEs, justifying costs and possible side effects of an asthma therapy during winter time.

\section{KARGER}

E-Mail karger@karger.com

www.karger.com/res
C 2016 S. Karger AG, Basel

0025-7931/16/0912-0107\$39.50/0
Johannes Schulze

Department of Allergy, Pulmonology and Cystic Fibrosis

Children's Hospital, Goethe University, Theodor Stern Kai 7

DE-60590 Frankfurt am Main (Germany)

E-Mail johannes.schulze@kgu.de 
Spirometry and methacholine challenge testing (MCT) are common predictors of AEs [3]. In our previous study [6] of 102 children (aged 4-7 years) with intermittent asthma, biomarkers and asthma characteristics were evaluated as predictors of treatment response either to montelukast or fluticasone. The biomarkers were the forced expiratory volume in $1 \mathrm{~s}\left(\mathrm{FEV}_{1}\right)$, the $\mathrm{FEV}_{1} / \mathrm{FVC}$ ratio, exhaled nitric oxide, and bronchial hyperresponsiveness (BHR) to methacholine. Forty-five percent of the children experienced an $\mathrm{AE}$ during a one-year observation period. In a post-hoc analysis, $\mathrm{FEV}_{1}$, the $\mathrm{FEV}_{1} / \mathrm{FVC}$ ratio, and $\mathrm{PD}_{20}$ methacholine significantly predicted moderate AEs.

The impulse oscillation system (IOS) is a simple, noninvasive method requiring only passive patient cooperation and may be useful in testing patients who cannot perform acceptable spirometry maneuvers $[7,8]$. IOS allows for the evaluation of lung function through the measurement of both airway resistance (Rrs) and airway reactance (Xrs) $[9,10]$. IOS generates pressure oscillations that are applied at a fixed (square wave) frequency of $5 \mathrm{~Hz}$, from which all other frequencies of interest are derived [9]. The Rrs includes proximal and distal airways (central and peripheral), lung tissue, and chest wall resistance [11]. Low-frequency, capacitive Xrs essentially expresses the ability of the respiratory tract to store capacitive energy, primarily resident in the lung periphery. Thus, Xrs5 characterizes the lung periphery [11].

Peripheral airways have much smaller lumina than central (large) airways, and inflammation/edema in the walls of peripheral airways can be expected to have a proportionately larger effect on lumen size than inflammation/edema in larger airways [11]. Many authors state that, when either proximal or distal airway obstruction occurs, Rrs5 and Xrs5 may be increased $[9,11]$, and higher-frequency oscillations, such as at $20 \mathrm{~Hz}$, provide information primarily concerning the central airways [9]. As a consequence, the difference between Rrs5 and Rrs20 (Rrs5-20) might be an index of the peripheral airways only [12]. Although, these findings are still hypothetical, there is a body of evidence suggesting that the forced oscillation technique (FOT) is more sensitive than spirometry to detect peripheral airway disease [11]. Many reports have found a frequency dependence of resistance and reactance in peripheral airways diseases, where the Rrs at low frequencies was greater than the Rrs at increased oscillation frequencies [13-17].

In 4-year-old children at risk of persistent asthma, Rrs 5 after bronchodilator response differentiates between children with and those without asthma [18]. Therefore,
IOS/FOT is an alternative in young children, not only because oscillation techniques are more applicable in this age group, but also because body plethysmograph or MCT cannot be easily performed in many centers.

Predictive models use clinical variables, healthcare data, pulmonary function testing (PFT), and biomarkers [4]. Data from young children are rare, because most studies only enroll children of the age of 6 years and older, and the outcome parameters are usually severe and not moderate AEs. To the best of our knowledge, no study has investigated IOS as a possible predictor of AEs in this age group so far. A study of children between 0 and 14 years of age observed that oral steroid prescriptions and hospitalizations indicated an increased risk of future hospitalization [5]. In school children, a lower $\mathrm{FEV}_{1} / \mathrm{FVC}$ ratio and the MCT were predictors of severe AEs [3]. Given the heterogeneity of young children with intermittent asthma and the urgency to identify only those with a high risk of AEs, we aimed to confirm our previous findings in a prospective cohort of 69 children with intermittent asthma. Following the same design, the validation of $\mathrm{FEV}_{1}$, the $\mathrm{FEV}_{1} / \mathrm{FVC}$ ratio, and MCT were the aim, as well as a skin prick or a RAST test was performed. Additionally, IOS was measured to identify patients with an occult elevation of airway resistance and reactance.

\section{Materials and Methods}

\section{Subjects}

Seventy-five children (4-7 years old) were evaluated after being recruited in the summer from the outpatient clinic of the Department of Allergy, Pulmonology and Cystic Fibrosis. All children were diagnosed with intermittent asthma by the investigator. The detailed patient history included asthma symptoms, comorbidities, allergies, and medication use. According to the GINA guidelines for asthma management and prevention in children 5 years and younger, symptom patterns were wheeze, cough, breathlessness, activity limitation, and nocturnal symptoms. Furthermore, the family history was recorded, particularly with regards to asthma, hay fever, and atopic dermatitis. Children were eligible for the study if they had either three episodes of wheeze lasting $>3$ days (confirmed by either the primary-care doctor or the investigator), or one prolonged physician-confirmed wheezy episode treated with inhaled corticosteroid (ICS) with a daily minimum dose of $100 \mu \mathrm{g}$ fluticasone or $200 \mu \mathrm{g}$ budesonide, or with leukotriene receptor antagonist (LTRA) for at least 6 weeks in the last 12 months. The parents were informed about the purpose, course, and aim of the study.

At the first visit, the children had to be free of infections during the previous 4 weeks according to the judgment of the investigator. Before the visit, short-acting beta-agonists were withdrawn for $8 \mathrm{~h}$, ipratropium bromide and long-acting beta-agonists were withdrawn for $48 \mathrm{~h}$, and ICS and LTRA were withdrawn for 28 days. 
The study was approved by the Ethics Committee of Goethe University, and informed consent was obtained from the participants' parents prior to the start of the study (clinical trials registration No.: NCT01449435).

\section{Study Design}

This nonblinded, cross-sectional study is based on 1 office visit and 6 telephone calls and took place between August 2011 and July 2012. At visit 1, baseline measurements were performed, including PFT, IOS, and MCT, as well as a skin prick or a RAST test. At the beginning of the study, IOS was not measured (in 15 of 69 patients), because IOS was only later added to the study protocol. The patients were followed for 1 year during the winter and spring seasons. The severity of the symptoms was calculated according to a validated pediatric asthma caregiver diary [19]. The parents were instructed to record in a diary all asthma symptoms, including cough, shortness of breath, and wheezing, as well as the use of salbutamol and systemic steroids, and signs of infections (runny nose and fever). Moderate AEs were defined as the occurrence of asthma symptoms and the use of salbutamol $\geq 2$ times per week or the use of $\geq 5$ puffs of salbutamol over a 2 -week period $[6,20]$. The parents were contacted by telephone every 2 months.

\section{IOS and PFT}

Using the Impulse Oscillometry System and Masterscreen (CareFusion, Hoechberg, Germany), IOS was measured first by a pulmonary function technician or by a trained $\mathrm{PhD}$ candidate. The system was calibrated daily as directed by the manufacturer. The mean of at least three technically acceptable maneuvers was determined. IOS data are presented as absolute values, they were adjusted for height and weight by the system according to the regression equations of Dencker et al. [21] and are presented as the percent of the predicted values. The intrameasurement repeatability is expressed as a coefficient of variation (CV) [22]. The mean of at least three technically acceptable maneuvers was determined.

IOS was followed by spirometry. The flow-volume curves were inspected and visibly inadequate maneuvers were excluded. The start of the test has been quantified by calculating the back-extrapolated volume, and the forced expired time has been reported. A minimum of two acceptable flow volume loops were required, and the second highest FVC and $\mathrm{FEV}_{1}$ were within 0.1 liters or $10 \%$ of the highest value [22]. The predicted $\mathrm{FEV}_{1}$ values were determined based on the reference values for children [23].

\section{Methacholine Challenge Testing}

MCT was performed using the APS dosimeter technique (CareFusion, Hoechberg, Germany) with the Sidestream, MedicAid nebulizer. The doses of inhaled methacholine, at a concentration of $16 \mathrm{mg} / \mathrm{ml}$, were increased according to the following specifications (steps 1-5): 0.01, 0.1, 0.4, 0.8, and $1.6 \mathrm{mg}$. Therefore, the entire protocol called for the delivery of cumulative doses of 0.1 , $0.5,1.3$, and $2.9 \mathrm{mg}$. Two min after each inhalation, spirometry was performed. The individual provocation dose that caused a $20 \%$ drop in $\mathrm{FEV}_{1}\left(\mathrm{PD}_{20}\right.$ methacholine) was calculated by logarithmic interpolation [24].

\section{Statistical Analysis}

For the statistical analyses, GraphPad Prism 5.01 (GraphPad Software, La Jolla, Calif., USA), BiAS for Windows version 11 (epsilon-Verlag; Darmstadt, Germany) and Microsoft Excel were used. The parameters were tested for normal and log-normal distributions using the Kolmogorov-Smirnov test. Fisher's exact test was used to determine associations between the variables in the contingency tables. To define the sensitivity and specificity of a predictor for detecting an $\mathrm{AE}$, a receiver-operating characteristic (ROC) curve was plotted. The cut-off levels were optimized using the Youden index (sensitivity + specificity -1$)$. The accuracy was measured with an area under the curve (AUC) analysis. The individual probability of an AE was calculated by logistic and log-logistic regression analyses. All predictor variables that are useful in predicting the response variable were included [25]. The Wald test was used to determine statistical significance for each of the independent variables. In a stepwise regression, significant variables were added to the model/prediction and nonsignificant variables were removed. Probability $(p)$ values $\leq 0.05$ were considered statistically significant.

Based on the post-hoc analysis including 102 children, an $\mathrm{FEV}_{1}$ of $103.2 \%$ pred, an $\mathrm{FEV}_{1} / \mathrm{FVC}$ ratio of $89.7 \%$, and a $\mathrm{PD}_{20}$ methacholine of $0.13 \mathrm{mg}$ significantly predicted an $\mathrm{AE}$. In the analysis, 17 of the 23 patients with 3 positive predictors and 5 of the 26 patients without positive predictors had AEs. To calculate the risk of exacerbation with an alpha of 0.05 and a beta of 0.20 , each group required a minimum of 12 patients. Because $16.2 \%$ of the children had 3 risk factors, and $18.3 \%$ of the children lacked any risk factors, a total group size of 75 patients was determined to include 12 patients in each group.

\section{Results}

Seventy-five pediatric patients were included, and 69 patients completed the study protocol. Of these, 51 children $(73.9 \%)$ had a first-degree family history of asthma, allergic rhinitis, or atopic dermatitis. Three patients were excluded because they were treated with ICS or LTRA without having AEs. In 3 cases, the parents withdrew consent. In the previous 12 months, 37 children (53.6\%) had undergone therapy with ICS, 25 (36.2\%) with LTRA, and $7(10.2 \%)$ with ICS and LTRA. During the observation period, 42 patients $(60.9 \%)$ had an AE. The AE was defined according to the inclusion criteria. Patients were advised to visit the study center immediately, and the $\mathrm{AE}$ was confirmed by the investigator. At the same time, the investigator decided about further asthma therapy.

There was a trend of younger children having more exacerbations; however, in the total group, this trend was not statistically significant $(\mathrm{p}=0.26)$. The baseline characteristics of all children are summarized in table 1.

Taken from the medical history of the 69 patients, 11 children (15.9\%) had allergic rhinitis, and 20 children (29.0\%) had atopic dermatitis. Twenty-seven patients had a positive skin prick or RAST test; 8 were mono-sensitized against grass, birch, alternaria, or mites; 6 had two sensitizations against grass/birch or mites/cats; and 13 
Table 1. Patient characteristics

\begin{tabular}{lllll}
\hline & Intention to treat & Per protocol & Exacerbated & Not-exacerbated \\
\hline Total & 75 & 69 & $42(60.9 \%)$ & $27(39.1 \%)$ \\
Male/female & $43 / 32$ & $38 / 31$ & $24 / 18$ & $19 / 8$ \\
Age, years & $5.0 \pm 0.82$ & $5.0 \pm 0.81$ & $4.9 \pm 0.83$ & $5.1 \pm 0.82$ \\
Age groups & & & & 7 \\
$\quad$ 4-5 years & 25 & 23 & 16 & 10 \\
$\quad 5-6$ years & 25 & 24 & 14 & 10 \\
$\quad 6-7$ years & 25 & 22 & 12 & $116.0 \pm 6.8$ \\
Height, cm & $114.8 \pm 8.1$ & $114.9 \pm 8.3$ & $114.1 \pm 9.0$ & $21.9 \pm 3.6$ \\
Weight, kg & $20.6 \pm 3.9$ & $21.2 \pm 4.0$ & $20.1 \pm 4.1$ & \\
\hline
\end{tabular}

Values are given as numbers or means $\pm \mathrm{SD}$.

Table 2. Baseline pulmonary lung function, MCT, per protocol group $(n=69)$ and IOS measurements $(n=54)$

\begin{tabular}{lcccc}
\hline & Total & Exacerbated & Not-exacerbated & $\mathrm{p}$ \\
\hline FVC, \% pred & $105.0 \pm 18.8$ & $103.2 \pm 20.6$ & $108.1 \pm 15.3$ & 0.29 \\
$\mathrm{FEV}_{1}, \%$ pred & $106.6 \pm 14.3$ & $104.6 \pm 13.9$ & $110.5 \pm 14.5$ & 0.10 \\
$\mathrm{FEV}_{1} / \mathrm{FVC}$ ratio, \% & $88.8 \pm 10.5$ & $88.0 \pm 9.7$ & $90.2 \pm 11.8$ & 0.41 \\
$\mathrm{PD}_{20}$ methacholine, $\mathrm{mg}$ & $0.34 \pm 0.55$ & $0.27 \pm 0.49$ & $0.45 \pm 0.63$ & 0.18 \\
$\mathrm{Rrs5}, \mathrm{kPa} \times \mathrm{l}^{-1} \times \mathrm{s}$ & $0.76 \pm 0.19$ & $0.84 \pm 0.19$ & $0.66 \pm 0.15$ & $<0.001$ \\
$\mathrm{Rrs5} \%$ pred & $95.1 \pm 28.0$ & $103.5 \pm 30.4$ & $85.5 \pm 21.6$ & $<0.01$ \\
$\mathrm{Xrs5}, \mathrm{kPa} \times \mathrm{l}^{-1} \times \mathrm{s}$ & $-0.28 \pm 0.12$ & $-0.32 \pm 0.12$ & $-0.24 \pm 0.11$ & 0.01 \\
$\mathrm{Xrs5} \%$ pred & $94.3 \pm 46.6$ & $104.9 \pm 50.3$ & $82.1 \pm 39.5$ & 0.07 \\
$\mathrm{Rrs5}-20, \mathrm{kPa} \times \mathrm{l}^{-1} \times \mathrm{s}$ & $0.37 \pm 0.14$ & $0.30 \pm 0.12$ & $0.42 \pm 0.13$ & $<0.001$ \\
\hline
\end{tabular}

Values are given as means $\pm \mathrm{SD}$.

Table 3. ROC analysis to detect an AE

\begin{tabular}{|c|c|c|c|c|c|}
\hline & $\begin{array}{l}\text { Optimal } \\
\text { cut-off point }\end{array}$ & $\begin{array}{l}\text { Sensitivity } \\
(95 \% \text { CI) }\end{array}$ & $\begin{array}{l}\text { Specificity } \\
(95 \% \text { CI })\end{array}$ & AUC & $\mathrm{p}$ \\
\hline $\mathrm{FEV}_{1}, \%$ pred & 100.9 & $0.43(0.28-0.59)$ & $0.74(0.54-0.89)$ & 0.61 & 0.10 \\
\hline $\mathrm{FEV}_{1} / \mathrm{FVC}$ ratio, $\%$ & 94.9 & $0.48(0.32-0.64)$ & $0.56(0.35-0.75)$ & 0.54 & 0.58 \\
\hline $\mathrm{PD}_{20}$ methacholine, $\mathrm{mg}$ & 0.14 & $0.55(0.38-0.71)$ & $0.26(0.11-0.46)$ & 0.61 & 0.11 \\
\hline Rrs5, $\mathrm{kPa} \times \mathrm{l}^{-1} \times \mathrm{s}$ & 0.76 & $0.68(0.49-0.83)$ & $0.83(0.56-0.93)$ & 0.78 & $<0.001$ \\
\hline Rrs5, \% pred & 95.0 & $0.58(0.39-0.75)$ & $0.76(0.55-0.90)$ & 0.69 & 0.01 \\
\hline $\mathrm{Xrs} 5, \mathrm{kPa} \times \mathrm{l}^{-1} \times \mathrm{s}$ & -0.4 & $0.29(0.18-0.52)$ & $1.0(0.85-1.00)$ & 0.70 & 0.01 \\
\hline Xrs5, \% pred & 128.8 & $0.32(0.17-0.51)$ & $0.92(0.74-0.99)$ & 0.61 & 0.14 \\
\hline Rrs5-20, $\mathrm{kPa} \times \mathrm{l}^{-1} \times \mathrm{s}$ & 0.3 & $0.90(0.74-0.98)$ & $0.57(0.34-0.77)$ & 0.77 & $<0.001$ \\
\hline
\end{tabular}

had a positive test against $\geq 3$ allergens. More prick or RAST test-positive children had exacerbations ( 22 positive vs. 5 non-positive children, respectively), and the non-sensitized patients were equally divided into the ex- acerbated and not-exacerbated groups (21 each). The differences were statistically significant $(\mathrm{p}=0.01)$, with a sensitivity of $51 \%$ (95\% CI, $0.35-0.67)$ and a specificity of $81 \%$ (95\% CI, 0.61-0.93). 
Table 4. Logistic regression to predict an $\mathrm{AE}$

\begin{tabular}{|c|c|c|c|}
\hline Predictor variables & $\begin{array}{l}\text { Regression } \\
\text { coefficient }\end{array}$ & AUC (95\% CI) & $\mathrm{p}$ \\
\hline $\mathrm{FEV}_{1}(\%$ pred $)$ & -0.03 & $0.63(0.49-0.77)$ & 0.10 \\
\hline $\mathrm{PD}_{20}$ methacholine (mg) & -0.58 & $0.62(0.48-0.76)$ & 0.11 \\
\hline $\mathrm{FEV}_{1} / \mathrm{FVC}$ ratio $(\%)$ & 0.003 & $0.54(0.40-0.68)$ & 0.57 \\
\hline $\operatorname{Rrs5}\left(\mathrm{kPa} \times \mathrm{l}^{-1} \times \mathrm{s}\right)$ & 7.44 & $0.78(0.68-0.92)$ & $<0.001$ \\
\hline Xrs5 $\left(\mathrm{kPa} \times \mathrm{l}^{-1} \times \mathrm{s}\right)$ & -7.90 & $0.70(0.56-0.84)$ & 0.01 \\
\hline $\mathrm{FEV}_{1}(\%$ pred $)$ & -0.03 & & \\
\hline $\mathrm{PD}_{20}$ methachloline (mg) & -0.54 & $0.6 /(0.53-0.80)$ & 0.02 \\
\hline $\operatorname{Rrs5}\left(\mathrm{kPa} \times \mathrm{l}^{-1} \times \mathrm{s}\right)$ & 7.40 & $0.84(0.74-$ & \\
\hline $\mathrm{FEV}_{1}(\%$ pred $)$ & -0.05 & & 0.0 \\
\hline $\operatorname{Rrs5}\left(\mathrm{kPa} \times 1^{-1} \times \mathrm{s}\right)$ & 7.56 & & \\
\hline $\mathrm{FEV}_{1}(\%$ pred $)$ & -0.05 & $0.87(0.77-0.96)$ & $<0.001$ \\
\hline $\mathrm{PD}_{20}$ methacholine (mg) & -1.33 & & \\
\hline
\end{tabular}

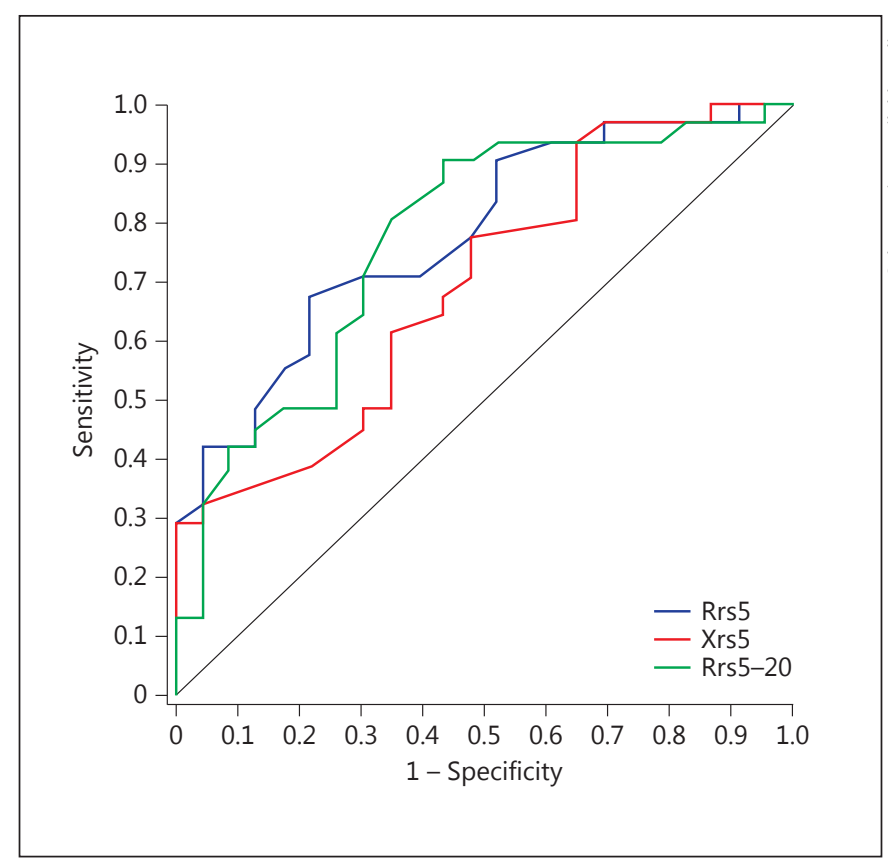

Fig. 1. ROC curves and optimal cut-offs to predict an AE. An Rrs5 value of $0.76 \mathrm{kPa} \times \mathrm{l}^{-1} \times \mathrm{s}$ predicted an $\mathrm{AE}$ with a sensitivity of $68 \%$ and a specificity of $83 \%$ (AUC $0.80, \mathrm{p}<0.001$ ), an Xrs5 value of $-0.4 \mathrm{kPa} \times \mathrm{l}^{-1} \times \mathrm{s}$ with a sensitivity of $29 \%$ and a specificity of $100 \%$ (AUC $0.70, \mathrm{p}=0.01$ ), and an Rrs5-20 value of $0.3 \mathrm{kPa} \times \mathrm{l}^{-1} \times \mathrm{s}$ with a sensitivity of $90 \%$ and a specificity of $57 \%$ (AUC $0.77, \mathrm{p}<0.001$ ).

\section{Pulmonary Function Testing}

The baseline PFT and MCT did not differentiate between the exacerbated and not-exacerbated groups. In three IOS measurements, the mean values, SD, and CV for Rrs5 and Xrs5 were $0.76 \mathrm{kPa} \times \mathrm{l}^{-1} \times \mathrm{s} \pm 0.19(\mathrm{CV}$ $26.1 \%)$ and $-0.28 \mathrm{kPa} \times \mathrm{l}^{-1} \times \mathrm{s} \pm 0.12(\mathrm{CV} 43.3 \%)$, respectively. In 54 patients, Rrs5, Xrs5, and Rrs5-20 differed significantly between the two groups (table 2).

\section{AE Predictors}

In the post-hoc analysis, $\mathrm{FEV}_{1}$, the $\mathrm{FEV}_{1} / \mathrm{FVC}$ ratio, and $\mathrm{PD}_{20}$ methacholine predicted moderate AEs in a ROC analysis. This result was not confirmed by the present data, as all measurements did not significantly predict AEs (table 3). Of the patients in this study, 16 had no positive predictors, 29 had 1, 17 had 2, and 7 had 3. Therefore, the calculated minimum of 12 patients was not reached in the groups with 3 positive predictors. To compare the groups, only the group with $0-1$ risk factors, consisting of 45 patients, and the group with $2-3$ predictors, consisting of 24 patients, had sufficient statistical power. Fisher's exact test demonstrated no significant between-group differences $(p=0.09)$.

In contrast, an Rrs5 level of $0.76 \mathrm{kPa} \times \mathrm{l}^{-1} \times \mathrm{s}$ predicted an $\mathrm{AE}$ with a sensitivity of $68 \%$ and a specificity of $83 \%$. The accuracy (AUC) was 0.78 ( $\mathrm{p}<0.001)$. An Xrs5 level of $-0.4 \mathrm{kPa} \times \mathrm{l}^{-1} \times \mathrm{s}$ predicted an $\mathrm{AE}$ with a sensitivity of $29 \%$ and a specificity of $100 \%$ (AUC $0.70, p=0.01$ ), and an Rrs5-20 level of $0.3 \mathrm{kPa} \times \mathrm{l}^{-1} \times \mathrm{s}$ predicted an AE with a sensitivity of $90 \%$ and a specificity of $57 \%$ (AUC 0.77 , p $<0.001$; fig. 1, table 3). Rrs5 and Xrs5 linearly declined with increasing height [21]. However, the accuracy of the reference values of Rrs5 and Xrs5 was inferior to that of the absolute values (table 3 ).

Younger children have more AEs. In our study group, Spearman's correlation test indicated that the coefficient of Rrs5 and height was $r=-0.17(p=0.20)$. In the next step, we adjusted the Rrs5 values for height by the regression coefficient of -0.0037 . The adjusted ROC analysis of Rrs5 revealed a sensitivity of $48.4 \%$ and a specificity of 95.7\% (AUC 0.76, 95\% CI 0.64-0.89, p < 0.001). Xrs5 was less dependent on height, with a correlation coefficient $r=-0.05$. Therefore, we did not adjust the Xrs5 values for height.

\section{Logistic Regression Models}

The different parameters were calculated in a stepwise logistic regression model. Rrs5 predicted an AE with an accuracy of $78 \%$, and Xrs5 predicted an AE with an accuracy of $70 \%$. Adding the variables age, gender, and height to Rrs5, all three variables did not significantly increase the predictive value of Rrs5. FEV 1 and $\mathrm{PD}_{20}$ methacholine were not significant as single values, but they were significant combined in the stepwise regression. The 
combination of Rrs5, $\mathrm{FEV}_{1}$, and $\mathrm{PD}_{20}$ methacholine demonstrated the best accuracy (i.e., $87 \%$, table 4 ) at $\mathrm{p}=1 \times$ $\left(1+\exp \left[-0.5510+(7.56 \times\right.\right.$ Rrs5 $)+\left(-0.05 \times \mathrm{FEV}_{1}\right)+$ $\left(-1.33 \times \mathrm{PD}_{20}\right.$ methacholine $\left.\left.\left.)\right]\right)^{-1} ; \mathrm{AUC}=0.87, \mathrm{p}<0.001\right)$.

\section{Discussion}

In this study, we aimed to confirm predictors of AEs. In contrast to the post-hoc analysis, the biomarkers $\mathrm{FEV}_{1}$, $\mathrm{FEV}_{1} / \mathrm{FVC}$ ratio, and $\mathrm{PD}_{20}$ methacholine did not predict AEs. However, IOS measured by simple maneuvers significantly predicted the probability of AEs. To the best of our knowledge, we are the first group to report that IOS measurements have a high predictive value in this age group. The combination with spirometry and MCT increased the accuracy in a logistic regression model.

In a large retrospective cohort study [26], $\mathrm{FEV}_{1}$ was an independent predictor of asthma attacks. For children with an $\mathrm{FEV}_{1}$ of $80-100 \%$ compared to children with an $\mathrm{FEV}_{1}>100 \%$, the odds ratios were 1.1 (CI, 1.0-1.2) in younger and 1.3 (CI, 1.1-1.4) in older patients. Decreasing $\mathrm{FEV}_{1}$ categories were associated with a progressive increase of individuals reporting an asthma attack. In the Childhood Asthma Management Program (CAMP) [3], the age at randomization, $\mathrm{FEV}_{1}$, the $\mathrm{FEV}_{1} / \mathrm{FVC}$ ratio, $\mathrm{PC}_{20}$ methacholine, and the number of positive skin tests at randomization differed significantly between those subjects who had no severe exacerbations and those who had at least one severe exacerbation.

In our post-hoc analysis, the spirometric parameter, $\mathrm{FEV}_{1}$, was identified as a predictor of AE. In the prospective study, even when $\mathrm{FEV}_{1}$ differed between the exacerbated and not-exacerbated groups, this failed to reach significance because of the lower sensitivity. In the cited studies with significant outcomes $[3,26]$, more severe patients with lower $\mathrm{FEV}_{1}$ values were investigated. In mild asthmatics, $\mathrm{FEV}_{1}$ might not be sensitive enough to detect moderate AEs.

IOS measurement significantly predicted AEs. In recent years, the clinical value of IOS and spirometry has been compared. In 4-year-old children at risk of persistent asthma, Rrs5 after bronchodilator response differentiated between children with and those without asthma [18]. At the same time, there were no significant differences in the spirometric values. Song et al. [27] confirmed these findings in 3- to 6-year-old children, and Komarow et al. [28] confirmed these findings in 3- to 17-year-old children and adolescents. In another study, 6- to 17-yearold children with controlled and uncontrolled asthma were compared [29]. The IOS measurements (not the $\mathrm{FEV}_{1}$ values) were significantly different between the two groups, and the authors hypothesized that the asthma control status primarily reflects small or peripheral airway obstruction. The same working group showed in the same age group that IOS significantly predicted children at risk of losing asthma control [12]. Lowe et al. [30] showed that 3-year-old children with a history of wheezing had a significantly higher specific airway resistance in body plethysmography than those who had never wheezed. In adults, using the multiple-breath nitrogen washout technique, asthma control was associated with small-airways disease [31]. In addition, it has recently been shown in adults with asthma that the IOS parameters Rrs5 and Rrs20, but not Rrs5-20 and AX, are associated with asthma severity, control, quality of life, and exacerbations [32].

The difference between 'large central' airways and 'small peripheral' airways is neither precisely fixed anatomically nor precisely defined in terms of airway lumen diameter [11]. In children with respiratory symptoms who had not yet been diagnosed with asthma, early eosinophilic inflammation and even remodeling of the airway wall has been detected in endobronchial biopsies [33]. Transbronchal biopsy studies in children are obsolete.

Nevertheless, apart from lung function testing, highresolution computed tomography has allowed for the detection of low-attenuation lung areas, which are believed to represent trapped air as a result of small airway closures [34]. In this study by Jain et al. [34], significant correlations between low-density areas on high-resolution computed tomography and the IOS parameters Rrs5 and Xrs5 were demonstrated in 21 children with mild to moderate asthma. FEV 1 and Rrs20 are more related to larger airways, whereas Rrs5-20 and Xrs5 represent peripheral airways. In our study, this result indicates that even during symptom-free intervals, impaired peripheral airways are present in children with intermittent asthma, and these children experience AEs during infections. As testing of the predictive value of IOS was not the primary aim of the study, the results are more exploratory than conclusive. Future studies are needed to confirm the results in a prospective cohort.

Shi et al. [29] performed a ROC analysis, and an Rrs5 value of $5.2 \mathrm{~cm} \mathrm{H}_{2} \mathrm{O} \times \mathrm{l}^{-1} \times \mathrm{s}\left(=0.51 \mathrm{kPa} \times \mathrm{l}^{-1} \times \mathrm{s}\right.$, AUC $0.71)$ and an Rrs5-20 value of $1.5 \mathrm{~cm} \mathrm{H}_{2} \mathrm{O} \times \mathrm{l}^{-1} \times \mathrm{s}(=0.15$ $\mathrm{kPa} \times 1^{-1} \times \mathrm{s}$, AUC 0.86 ) best discriminated between controlled and uncontrolled asthma. Concerning the prediction of loss of asthma control [12], the accuracy of Rrs5 
equaled our results ( 0.80 vs. 0.78 ), whereas the accuracy of Rrs5-20 was better ( 0.91 vs. 0.78$)$ in Shi et al.'s study [12]. The optimal cut-off points of $5.4 \mathrm{~cm} \mathrm{H}_{2} \mathrm{O} \times \mathrm{l}^{-1} \times \mathrm{s}$ for Rrs5 $\left(=0.53 \mathrm{kPa} \times \mathrm{l}^{-1} \times \mathrm{s}\right)$ and $1.0 \mathrm{~cm} \mathrm{H}_{2} \mathrm{O} \times \mathrm{l}^{-1} \times \mathrm{s}$ for Rrs5-20 (=0.1 kPa $\left.\times 1^{-1} \times \mathrm{s}\right)$ were lower than our results of $0.76 \mathrm{kPa} \times \mathrm{l}^{-1} \times \mathrm{s}$ for Rrs5 and $0.3 \mathrm{kPa} \times \mathrm{l}^{-1} \times \mathrm{s}$ for Rrs5-20 when predicting exacerbations. We, however, analyzed younger children, and resistance has been shown to correlate with height and to decrease in older children $[21,29,35]$. Furthermore, the ROC analyses of Rrs5-20 and Xrs5 were superior to that of Rrs5 [12, 29]. In our study, the predictive accuracy of Rrs 5 equaled that of Rrs5-20. Interestingly, in our study, the stratification for height only marginally altered the predictive value of Rrs5, indicating that Rrs5 is an independent parameter in this age group. In the ROC analysis, Xrs5 and the adjusted Rrs5 values revealed a low sensitivity and a high specificity. Shi et al. [12] showed that a lower cut-off point for $\mathrm{Xrs} 5\left(-1.8 \mathrm{kPa} \times \mathrm{l}^{-1} \times \mathrm{s}\right)$ achieved a better balance between sensitivity and specificity. We found no examples for height-adjusted Rrs5 values in the literature.

In our study, the absolute values of Rrs 5 and Xrs5 were superior to the reference values. A comparison with the literature is difficult, because mainly absolute values are presented $[12,18,27,29]$. It is possible that a sample of 360 children [21] is not enough for exact reference values, and absolute values continue to be more precise.

In the study by Bisgaard and Klug [7] that included 21 young children aged 4-6 years, Rrs and Xrs both exhibited the strongest response at $5 \mathrm{~Hz}$ during a methacholine challenge. Further studies showed equal responses of Rrs5 and Xrs5 [28, 29], suggesting a close relationship between Rrs5 and Xrs5, as hyperinflation measured by Xrs5 increases with increasing airway narrowing measured by Rrs5.

As a predictor of exacerbations, BHR has rarely been investigated in young children. In our study, similar to $\mathrm{FEV}_{1}, \mathrm{PD}_{20}$ methacholine was not a significant predictor on its own. In the Pediatric Asthma Controller Trial (PACT) [2], $\mathrm{PC}_{20}$ methacholine was not associated with exacerbations that required systemic corticosteroids or emergency care in mild to moderate asthmatics. Moderate exacerbations were not considered outcome parameters, and all patients received a controller medication that might have masked moderate AEs. In contrast, in the CAMP study [3], $\mathrm{PC}_{20}$ methacholine was significantly associated with severe exacerbations, even after adjusting for ICS.

Stepwise logistic regression models test the fit of a model after each coefficient is added or deleted [25]. The combination of $\mathrm{FEV}_{1}$ and $\mathrm{PD}_{20}$ metacholine revealed a significant accuracy on a low level, indicating that both predictors have implications. After adding both parameters to Rrs5, the individual probability for predicting a moderate AE increased.

Compared with non-atopic children, we found that atopy was a specific risk factor for AEs. Children (3-17 years old) who were admitted to the hospital with an acute AE were significantly more sensitized than controls with stable asthma or inpatient controls [36]. In the CAMP study [3], the number of positive skin tests differed significantly between subjects with 0 exacerbations and those with 1 severe exacerbation. In the MAAS study [30], atopic children had a higher specific airway resistance than non-atopic children.

The current study has some limitations. We could not confirm the hypothesis that children with 2-3 positive predictors $\left(\mathrm{FEV}_{1}, \mathrm{FEV}_{1} / \mathrm{FVC}\right.$ ratio, and $\mathrm{PD}_{20}$ methacholine) have more exacerbations than children with $0-1$ positive predictors. Children with $0-1$ positive predictors had more AEs, as expected; and only 7 children had 3 positive predictors, as opposed to the 12 calculated patients. Another limitation is the lack of data on post-bronchodilator reactivity. We did not define the IOS measurements as a primary outcome parameter. IOS was later included in the study; thus, it was measured in 54 of 69 patients. The highly significant between-group difference and $80 \%$ accuracy for differentiating between patients with and those without exacerbations demonstrate the prognostic value of the IOS measurements. In comparison, a questionnaire for predicting severe AEs in the CAMP cohort had an accuracy of $69 \%$ [4].

\section{Conclusions}

The single parameters $\mathrm{FEV}_{1}, \mathrm{FEV}_{1} / \mathrm{FVC}$ ratio, and BHR failed to predict moderate AEs in young children with asthma. In contrast, IOS was superior to spirometry and MCT with highly significant accuracy. In a stepwise regression, $\mathrm{FEV}_{1}$ and $\mathrm{MCT}$ increased the predictive value of Rrs5. As Rrs5-20 and Xrs5 represent peripheral airway obstruction and hyperinflation, respectively, there is evidence that the impairment of small airways is present even in the absence of symptoms. Future studies on AEs should include small airway measurements, such as IOS, body plethysmography, or the lung clearance index raised by the multiple breath washout test. In airway narrowing due to inflammation, the washout might take longer to complete, requiring a greater number of breaths [37]. 


\section{References}

$>1$ Swern AS, Tozzi CA, Knorr B, Bisgaard H: Predicting an asthma exacerbation in children 2-5 years of age. Ann Allergy Asthma Immunol 2008;10:626-630.

-2 Covar RA, Szefler SJ, Zeiger RS, Sorkness CA, Moss M, Mauger DT, Boehmer SJ, Strunk RC, Martinez FD, Taussig LM: Factors associated with asthma exacerbations during a longterm clinical trial of controller medications in children. J Allergy Clin Immunol 2008;122: 741-747.

-3 Wu AC, Tantisira K, Li L, Schuemann B, Weiss ST, Fuhlbrigge AL; Childhood Asthma Management Program Research Group: Predictors of symptoms are different from predictors of severe exacerbations from asthma in children. Chest 2011;140:100-107.

4 Forno E, Celedón JC: Predicting asthma exacerbations in children. Curr Opin Pulm Med 2012;18:63-69.

$\checkmark 5$ Lieu TA, Quesenberry CP, Sorel ME, Mendoza GR, Leong AB: Computer-based models to identify high-risk children with asthma. Am J Respir Crit Care Med 1998;157:11731180.

6 Zielen S, Christmann M, Kloska M, DoganYildiz G, Lieb A, Rosewich M, Schubert R, Rose MA, Schulze J: Predicting short term response to anti-inflammatory therapy in young children with asthma. Curr Med Res Opin 2010;26:483-492.

7 Bisgaard H, Klug B: Lung function measurement in awake young children. Eur Respir J 1995;8:2067-2075.

$>8$ Schulze J, Smith HJ, Fuchs J, Herrmann E, Dressler M, Rose MA, Zielen S: Methacholine challenge in young children as evaluated by spirometry and impulse oscillometry. Respir Med 2012;106:627-634.

$\checkmark 9$ Komarow HD, Myles IA, Uzzaman A, Metcalfe DD: Impulse oscillometry in the evaluation of diseases of the airways in children. Ann Allergy Asthma Immunol 2011;106: 191-199.

10 Bickel S, Popler J, Lesnick B, Eid N: Impulse oscillometry: interpretation and practical applications. Chest 2014;146:841-847.

$>11$ Smith HJ, Reinhold P, Goldman MD: Forced oscillation technique and impulse oscillometry. Eur Respir Mon 2005;31:72.

12 Shi Y, Aledia AS, Galant SP, George SC: Peripheral airway impairment measured by oscillometry predicts loss of asthma control in children. J Allergy Clin Immunol 2013;131: 718-723.

13 Clément J, Làndsér FJ, Van de Woestijne KP: Total resistance and reactance in patients with respiratory complaints with and without airways obstruction. Chest 1983;83:215-220.
14 Decramer M, Demedts M, Van de Woestijne $\mathrm{KP}$ : Isocapnic hyperventilation with cold air in healthy non-smokers, smokers and asthmatic subjects. Bull Eur Physiopathol Respir 1984;20:237-243.

15 Skloot G, Goldman M, Fischler D, Goldman C, Schechter C, Levin S, et al: Respiratory symptoms and physiologic assessment of ironworkers at the World Trade Center disaster site. Chest 2004;125:1248-1255.

-16 Brochard L, Pelle G, de Palmas J, Brochard P, Carre A, Lorino H, Harf A: Density and frequency dependence of resistance in early airway obstruction. Am Rev Respir Dis 1987; 135:579-584.

17 Kjeldgaard JM, Hyde RW, Speers DM, Reichert WW: Frequency dependence of total respiratory resistance in early airway disease. American Rev Respir Dis 1976;114:501-508.

18 Marotta A, Klinnert MD, Price MR, Larsen GL, Liu AH: Impulse oscillometry provides an effective measure of lung dysfunction in 4-year-old children at risk for persistent asthma. J Allergy Clin Immunol 2003;112:317322.

19 Santanello NC, Demuro-Mercon C, Davies G, Ostrom N, Noonan M, Rooklin A, et al: Validation of a pediatric asthma caregiver diary. J Allergy Clin Immunol 2000;106:861-866.

20 Reddel HK, Taylor DR, Bateman ED, et al: An official American Thoracic Society/European Respiratory Society statement: asthma control and exacerbations: standardizing endpoints for clinical asthma trials and clinical practice. Am J Respir Crit Care Med 2009; 180:59-99.

21 Dencker M, Malmberg LP, Valind S, Thorsson O, Karlsson MK, Pelkonen A, et al: Reference values for respiratory system impedance by using impulse oscillometry in children aged 2-11 years. Clin Physiol Funct Imaging 2006;26:247-250.

22 Beydon N, Davis SD, Lombardi E, et al: An official American Thoracic Society/European Respiratory Society statement: pulmonary function testing in preschool children. Am J Respir Crit Care Med 2007;175:1304-1345.

23 Quanjer PH, Borsboom GJ, Brunekreef B, et al: Spirometric reference values for white $\mathrm{Eu}$ ropean children and adolescents: Polgar re visited. Pediatr Pulmonol 1995;19:135-142.

24 Schulze J, Rosewich M, Riemer C, Dressler M, Rose MA, Zielen S: Methacholine challenge - comparison of an ATS protocol to a new rapid single concentration technique. Respir Med 2009;103:1898-1903.

25 Sarkar SK, Midi H: Importance of assessing the model adequacy of binary logistic regression. J Appl Sci 2010;10:479-486.

26 Fuhlbrigge AL, Kitch BT, Paltiel AD, Kuntz KM, Neumann PJ, Dockery DW, Weiss ST: $\mathrm{FEV}_{1}$ is associated with risk of asthma attacks in a pediatric population. J Allergy Clin Immunol 2001;107:61-67.
27 Song TW, Kim KW, Kim ES, Park JW, Sohn $\mathrm{MH}, \mathrm{Kim}$ KE: Utility of impulse oscillometry in young children with asthma. Pediatr Allergy Immunol 2008;19:763-768.

$>28$ Komarow HD, Skinner J, Young M, Gaskins D, Nelson C, Gergen PJ, Metcalfe DD: A study of the use of impulse oscillometry in the evaluation of children with asthma: analysis of lung parameters, order effect, and utility compared with spirometry. Pediatr Pulmonol 2012;47:18-26.

29 Shi Y, Aledia AS, Tatavoosian AV, Vijayalakshmi S, Galant SP, George SC: Relating small airways to asthma control by using impulse oscillometry in children. J Allergy Clin Immunol 2012;129:671-678.

30 Lowe L, Murray CS, Custovic A, Simpson BM, Kissen PM, Woodcock A; NAC Manchester Asthma and Allergy Study Group: Specific airway resistance in 3-year-old children: a prospective cohort study. Lancet 2002; 359:1904-1908.

-31 Farah CS, King GG, Brown NJ, Downie SR, Kermode JA, Hardaker KM, Peters MJ, Berend N, Salome CM: The role of the small airways in the clinical expression of asthma in adults. J Allergy Clin Immunol 2012;129:381387.

32 Gonem S, Natarajan S, Desai D, Corkill S, Singapuri A, Bradding $\mathrm{P}$, et al: Clinical significance of small airway obstruction markers in patients with asthma. Clin Exp Allergy 2014; 44:499-507.

-33 Pohunek P, Warner JO, Turzíková J, Kudrmann J, Roche WR: Markers of eosinophilic inflammation and tissue re-modelling in children before clinically diagnosed bronchial asthma. Pediatr Allergy Immunol 2005;16: 43-51.

34 Jain N, Covar RA, Gleason MC, Newell JD, Gelfand EW, Spahn JD: Quantitative computed tomography detects peripheral airway disease in asthmatic children. Pediatr Pulmonol 2005;40:211-218.

-35 Hellinckx J, De Boeck K, Bande-Knops J, van der Poel M, Demedts M: Bronchodilator response in 3-6.5 years old healthy and stable asthmatic children. Eur Respir J 1998;12:438443.

36 Murray CS, Poletti G, Kebadze T, Morris J, Woodcock A, Johnston SL, Custovic A: Study of modifiable risk factors for asthma exacerbations: virus infection and allergen exposure increase the risk of asthma hospital admissions in children. Thorax 2006;61:376-382.

37 Horsley A: Lung clearance index in the assessment of airways disease. Respir Med 2009; 103:793-799. 